\title{
Impact of a Single Intracoronary Administration of Adiponectin on Myocardial Ischemia/Reperfusion Injury in a Pig Model
}

\author{
Kazuhisa Kondo, MD, PhD, Rei Shibata, MD, PhD, Kazumasa Unno, MD, PhD, Masayuki \\ Shimano, MD, PhD, Masakazu Ishii, MSc, Tetsutaro Kito, MD, Satoshi Shintani, MD, PhD, \\ Kenneth Walsh, PhD, Noriyuki Ouchi, MD, PhD, and Toyoaki Murohara, MD, PhD \\ Department of Cardiology (K.K., R.S., K.U., M.S., M.I., T.K., S.S., T.M.), Nagoya University \\ Graduate School of Medicine, Showa-Ku, Nagoya, Japan; and Molecular Cardiology/Whitaker \\ Cardiovascular Institute (K.W., N.O.), Boston University School of Medicine, Boston, Mass.
}

\begin{abstract}
Background-Adiponectin plays a protective role in the development of obesity-linked disorders. We demonstrated that adiponectin exerts beneficial actions on acute ischemic injury in mice hearts. However, the effects of adiponectin treatment in large animals and its feasibility in clinical practice have not been investigated. This study investigated the effects of intracoronary administration of adiponectin on myocardial ischemia-reperfusion (I/R) injury in pigs.
\end{abstract}

Methods and Results-The left anterior descending coronary artery was occluded in pigs for 45 minutes and then reperfused for 24 hours. Recombinant adiponectin protein was given as a bolus intracoronary injection during ischemia. Cardiac functional parameters were measured by a manometer-tipped catheter. Apoptosis was evaluated by terminal deoxynucleotidyltransferasemediated dUTP nick end-labeling staining. Tumor necrosis factor- $a$ and interleukin-10 transcripts were analyzed by real-time polymerase chain reaction. Serum levels of derivatives of reactive oxygen metabolites and biological antioxidant potential were measured. Adiponectin protein was determined by immunohistochemical and Western blot analyses. Intracoronary administration of adiponectin protein led to a reduction in myocardial infarct size and improvement of left ventricular function in pigs after I/R. Injected adiponectin protein accumulated in the I/R-injured heart. Adiponectin treatment resulted in decreased tumor necrosis factor- $a$ and increased interleukin-10 mRNA levels in the myocardium after I/R. Adiponectin-treated pigs had reduced apoptotic activity in the I/R-injured heart and showed increased biological antioxidant potential levels and decreased derivatives of reactive oxygen metabolite levels in the blood stream after I/R.

Conclusions-These data suggest that adiponectin protects against I/R injury in a preclinical pig model through its ability to suppress inflammation, apoptosis, and oxidative stress. Administration of intracoronary adiponectin could be a useful adjunctive therapy for acute myocardial infarction.

\section{Keywords}

adiponectin; myocardial infarction; reperfusion

Copyright (C) 2010 American Heart Association. All rights reserved

Correspondence to Rei Shibata, MD, PhD, Department of Cardiology, Nagoya University Graduate School of Medicine, 65 Tsurumai, Showa-Ku, Nagoya 466-8550, Japan. rshibata@med.nagoya-u.ac.jp. Drs Kondo and Shibata contributed equally to the work.

The online-only Data Supplement is available at http://circinterventions.ahajournals.org/cgi/content/full/CIRCINTERVENTIONS. 109.872044/DC1.

Disclosures None. 
Acute myocardial infarction (AMI) is a major cause of death in industrial countries. ${ }^{1}$

Reperfusion therapy immediately after the onset of AMI has been shown to limit infarct size and preserve cardiac function. ${ }^{2,3}$ However, successful reperfusion determined by coronary angiography is not always accompanied by adequate reperfusion at the heart tissue level and improvement of cardiac dysfunction and injury in the chronic phase after AMI. ${ }^{4}$ Therefore, it is reasonable to develop a promising adjunctive therapy for patients with AMI.

Obesity-linked complications, including type 2 diabetes, dyslipidemia, and hypertension, have been shown to predict the severity and outcome of AMI. ${ }^{5,6}$ It has also been shown that obesity-related diseases are associated with increased cardiac damage and impaired left ventricular $(\mathrm{LV})$ function after successful percutaneous coronary intervention for AMI. 7,8

Adiponectin is an adipose-derived hormone, which plays a protective role in the development of obesity-linked disorders. In clinical studies, plasma adiponectin levels are down-regulated in association with cardiovascular risk factors, including type 2 diabetes, hypertension, dyslipidemia, and low-grade inflammation. ${ }^{9}$ Consistent with these clinical observations, a number of experimental studies show that adiponectin deficiency contributes to diet-induced insulin resistance, ${ }^{10}$ salt-sensitive hypertension, ${ }^{11}$ and impaired ischemiainduced neovascularization. ${ }^{12}$ Recently, several mouse studies demonstrated that adiponectin has beneficial effects on the heart under pathological conditions. Adiponectindeficient mice exhibit enhanced concentric cardiac hypertrophy after pressure overload. ${ }^{13,14}$ It has also been shown that adiponectin inhibits the development of severe myocarditis in leptin-deficient $o b / o b$ mice. ${ }^{15}$ With regard to myocardial infarction, ablation of adiponectin in mice causes increased infarct size and adverse cardiac remodeling after myocardial ischemia-reperfusion (I/R). ${ }^{16}$ Supplementation with adiponectin into wild-type and adiponectin-deficient mice leads to diminished infarct size and improved cardiac function. ${ }^{16}$ Adiponectin also exerts favorable actions on systolic dysfunction in wild-type mice after permanent coronary ligation. ${ }^{16}$ Consistent with these experimental observations, high adiponectin levels were associated with improvement of cardiac damage and function after reperfusion therapy in patients with AMI. ${ }^{17}$ Thus, adiponectin protein may have clinical utility in the treatment of patients with AMI. However, the effects of adiponectin treatment on acute cardiac injury in large animals and its feasibility in clinical practice have not been investigated. Here, we explore the potential therapeutic application of adiponectin in a largeanimal model by using the same instrumentation and standard of care as in humans. Our observations indicate that intracoronary injection of adiponectin could be a useful adjunctive therapy for AMI.

\section{Methods}

Methods are described in detail in the online-only Data Supplement. Please see the supplemental Methods.

\section{Pig Model of Myocardial I/R}

This study used domestic female Yorkshire-Duroc pigs (2 to 3 months old, $30.75 \pm 1.2 \mathrm{~kg}$; Nihon Crea, Tokyo, Japan). All procedures were approved by the institutional animal care and use committee and were conducted according to the institutional guidelines of Nagoya University School of Medicine. Animals were anesthetized with ketamine hydrochloride (20 $\mathrm{mg} / \mathrm{kg}$ ) and xylazine $(3.5 \mathrm{mg} / \mathrm{kg}$ ) and maintained with isoflurane (1\% to $2.5 \%)$ by ventilator after intubation. Animals were placed in the supine position, and the body temperature was kept in the normal range $\left(36^{\circ} \mathrm{C}\right.$ to $\left.37^{\circ} \mathrm{C}\right)$ by using a heating blanket. Vascular access was obtained with $7 \mathrm{~F}$ vascular sheaths, which were placed in the femoral arteries. After systemic heparinization (3000 IU/animal, with activated clotting time maintained at 200 to 300 seconds), hemodynamic measurement was performed with a $6 \mathrm{~F}$ catheter-tip manometer 
(CA-6100-PLB; CD Leycom Instrument, Zoetermeer, The Netherlands). Data were processed with Power Laboratory recording and analysis software (AD Instruments, Oxfordshire, UK) as described previously. ${ }^{18}$ Then, using a $6 \mathrm{~F}$ guiding catheter, we performed coronary angiography to determine the optimal location of the occlusion and assessment of coronary artery size after administration of nitroglycerine $(0.2 \mathrm{mg})$. Depending on the visual estimate of vessel size, an over-the-wire-type angioplasty balloon catheter (diameter, $3.0 \pm 0.5 \mathrm{~mm}$; length, $18 \mathrm{~mm}$; Boston Scientific Japan, Tokyo, Japan) was placed in the left anterior descending artery (LAD) distal to the first major diagonal branch. The balloon was inflated to occlude the LAD at 6 to $8 \mathrm{~atm}$ for 45 minutes. Localization of the coronary occlusion and patency of the first diagonal branch were confirmed by contrast injection and electrocardiographic ST-segment elevation (Figure 1A and 1B). Animals were randomly divided into 2 groups. After occlusion of the LAD, an intracoronary bolus of recombinant human adiponectin protein $(0.03 \mu \mathrm{g} / \mathrm{kg}$ in $10 \mathrm{~mL}$ saline per animal) or saline as a control was given through the wire lumen of the inflated balloon catheter during the first 10 minutes of coronary ischemia. During the procedure, blood pressure, heart rate, and the ECG were continuously recorded with a cardiac monitor. Life-threatening arrhythmias such as ventricular fibrillation (VF) were immediately terminated by electric cardioversion. After 45 minutes, the LAD balloon was deflated and restoration of normal coronary flow was documented by angiography. After 24 hours of reperfusion, animals were anesthetized and hemodynamic measurements were assessed as described earlier. Then animals were euthanized with an overdose of pentobarbital to excise the heart. Schematic illustrations of the experimental protocol are shown in Figure 1C.

\section{Results}

\section{Reduced Myocardial Infarct Size and Improved Cardiac Function After Adiponectin Therapy in Pigs}

Mortality and the incidence of VF after I/R are shown in the Table. Two pigs in the control group died within 24 hours after the procedure, whereas no animals in the adiponectin treatment group died $(P=0.48)$. Incidence of $\mathrm{VF}$ during $\mathrm{I} / \mathrm{R}$ was significantly lower in adiponectin-treated pigs than in control pigs $(P=0.01)$.

We examined the impact of intracoronary administration of adiponectin on infarct size. By gross morphological examination before excision of the heart, adiponectin treatment (compared with control) reduced myocardial infarct area (IA) after I/R (Figure 2A).

Representative photographs of myocardial tissues after staining with Evans blue dye to delineate the area at risk (AAR) and 2,3,5-triphenyl tetrazolium chloride to delineate the IA in pigs with control and adiponectin treatments are shown in Figure 2B. The AAR/LV was the same between the 2 groups (Figure 2C). Of importance, the IA/AAR and IA/LV ratios were significantly decreased by $42 \%$ and $48 \%$, respectively, in adiponectin-treated pigs compared with control pigs. Plasma troponin I level, an index of myocyte injury, was also significantly lower in adiponectin-treated pigs compared with control pigs after I/R (Figure 2D).

To examine the effect of adiponectin on cardiac function, we measured hemodynamic parameters in control and adiponectin-treated pigs at baseline and 24 hours after I/R by using a manometer-tipped catheter. There were no significant differences between the 2 groups at baseline in all hemodynamic parameters. Heart rate and LV pressure at 24 hours after I/R did not differ between the 2 groups (Figure 3A and 3B), whereas LV end-diastolic pressure and $\mathrm{T}_{1 / 2}$ showed a marked elevation in control pigs; the increase in LV enddiastolic pressure was diminished in the adiponectin-treated animals (Figure 3C and 3D). Furthermore, adiponectin treatment increased $\mathrm{d} P / \mathrm{d} t_{\max }$ and decreased $\mathrm{d} P / \mathrm{d} t_{\min }$ at 24 hours after I/R (Figure 3E and 3F). 


\section{Accumulation of Adiponectin in Injured Myocardium After Intracoronary Injection}

To examine whether exogenous adiponectin proteins are detected in the heart, immunohistochemical analysis of human adiponectin protein was performed at 24 hours after I/R. Representative photographs of myocardial tissue stained with anti-human adiponectin antibodies are shown in Figure 4A. Adiponectin protein was detected in the ischemic area of the myocardium at 24 hours after $\mathrm{I} / \mathrm{R}$ in pigs that had been treated with exogenous human adiponectin protein. In contrast, adiponectin protein was not detected in the ischemic myocardium of control pigs (without injection of adiponectin protein). There was little or no detectable adiponectin in nonischemic hearts of pigs. Western blotting analysis detected human adiponectin protein in ischemic hearts after injection of adiponectin protein, whereas little or no expression of adiponectin could be detected in sham-operated hearts and saline-treated ischemic hearts (Figure 4B). In addition, we assessed the phosphorylation of AMP-activated protein kinase and the expression of cyclooxygenase (COX)-2 in the heart by Western blot analysis, because adiponectin directly affects these signaling pathways in myocardial cells. ${ }^{16} \mathrm{I} / \mathrm{R}$ led to an increase in the level of AMPactivated protein kinase phosphorylation and the expression of cyclooxygenase-2 in pig hearts, but the magnitude of these inductions was greater in the adiponectin-treated pigs than in the control group (Figure 4C).

\section{Reduced Inflammatory Status After I/R by Adiponectin Treatment}

The activity of myeloperoxidase and myocardial levels of tumor necrosis factor (TNF)-a and interleukin (IL)-10 were assessed because increased inflammatory reactions contribute to myocardial injury. ${ }^{19}$ The myeloperoxidase activity in the ischemic tissue was markedly increased by $\mathrm{I} / \mathrm{R}$ injury, but this induction was significantly less in the adiponectin-treated pigs than in the control group (Figure 5A). Cardiac TNF-a mRNA was elevated by I/R injury, but this induction was attenuated by treatment with adiponectin (Figure 5B). In contrast, adiponectin promoted expression of the anti-inflammatory cytokine IL-10 (Figure 5C). There were no significant differences in these parameters between the 2 groups after sham operation. Thus, inflammation in the heart was reduced by adiponectin treatment.

\section{Decrease in I/R-Induced Apoptosis by Adiponectin Treatment}

Apoptosis is a feature of many pathological heart conditions. ${ }^{20}$ To investigate the antiapoptotic actions of adiponectin treatment, terminal deoxynucleotidyltransferasemediated dUTP nick end-labeling (TUNEL) staining was performed in the heart of control and adiponectin-treated pigs at 24 hours after I/R. Representative photographs of TUNELpositive nuclei in the myocardium are shown in Figure 6A. Quantitative analysis revealed a significantly lower proportion of TUNEL-positive cells in the ischemic area of adiponectintreated pigs compared with control pigs after I/R injury $(P=0.009)$, whereas little or no TUNEL-positive cells could be detected in the hearts of control or adiponectin-treated pigs after sham operation (Figure 6B). Conversion of the proapoptotic proenzyme caspase- 3 to the active cleaved form in the myocardium was increased in response to $I / R$, but the increase in cleaved caspase-3 was suppressed by adiponectin treatment (Figure 6C).

\section{Decreased Oxidative Damage After I/R Injury by Adiponectin Treatment}

Oxidative stress acts as the major mediator of $\mathrm{I} / \mathrm{R}$ injury. ${ }^{21}$ To investigate whether adiponectin has antioxidant potential, we measured serum levels of derivatives of reactive oxidative metabolites (d-ROMs), an index of oxidative stress, and biological antioxidative potential (BAP), an index of antioxidative activity. ${ }^{22,23} \mathrm{I} / \mathrm{R}$ led to an increase in serum dROMs and a decrease in serum BAP at 24 hours after I/R. Serum d-ROM levels were elevated by $\mathrm{I} / \mathrm{R}$ injury to a greater degree in control pigs than in adiponectin-treated pigs $(P=0.021)$. In contrast, serum BAP levels were significantly increased by adiponectin 
treatment $(P=0.007)$. Thus, adiponectin decreased oxidative damage after I/R injury (Figure $7 \mathrm{~A}$ and $7 \mathrm{~B})$.

\section{Discussion}

This is the first study to evaluate the effectiveness and feasibility of adiponectin treatment for AMI in a preclinical animal model that closely reproduces the current procedural management of AMI in humans. ${ }^{24,25} \mathrm{We}$ chose the pig model of I/R injury because of the similarity between porcine heart anatomy and that of the human heart and our ability to use the same instrumentation as is used in humans. ${ }^{24,25}$

Low adiponectin levels are observed in patients with acute coronary syndrome. ${ }^{26}$ It was shown that declining adiponectin levels after onset of AMI could be a positive predictor for future cardiac events. ${ }^{27}$ Recently, we demonstrated that plasma adiponectin levels are associated positively with improvements in damaged myocardial tissue and function after successful reperfusion therapy in patients with AMI, as estimated by scintigraphic image analysis. ${ }^{17}$ These data suggest that a therapeutic approach aimed at increasing adiponectin levels or its sensitivity to the heart could be useful for treating AMI. In experimental studies, it has been shown that adiponectin protects the heart from injury in response to I/R in mice. ${ }^{16} \mathrm{We}$ show here that intracoronary administration of adiponectin protein reduced myocardial infarct size and attenuated impaired cardiac function after I/R in a pig model. Thus, supplementation with adiponectin could be protective against reperfusion injury in patients with AMI.

Injected human adiponectin protein was detected in hearts after I/R injury but not in noninjured hearts in this model. However, we could not detect an increase in circulating levels of human adiponectin (data not shown), perhaps because the bulk of the endogenous protein was localized to the injured myocardium. In agreement with these findings, systemic delivery of adiponectin to adiponectin-deficient mice led to the accumulation of adiponectin in I/R-injured vasculature and hearts but not in uninjured tissue. ${ }^{28}$ We have also shown that adiponectin accumulates in injured vascular endothelium during cerebral ischemia in a mouse model of I/R. ${ }^{29}$ Our studies have also shown that adiponectin colocalizes with myocardial collagen type III, a major collagen in cardiac extracellular matrix. ${ }^{28}$ Consistent with these findings, it has been previously reported that adiponectin can bind to collagen types I, III, and IV in solid-phase binding assays. ${ }^{30}$ It is possible that an adiponectincollagen complex may be required for interaction with the receptor, ${ }^{31-33}$ as has been proposed for the adiponectin-T cadherin complex. ${ }^{34}$ However, the nature of the interaction between adiponectin and its receptors is poorly understood at this time. Collectively, the majority of exogenous adiponectin might enter into damaged myocardial tissue as a result of leakage from the vascular compartment after a bolus intracoronary delivery.

Inflammatory reactions play an important role in the progression of myocardial injury after $\mathrm{I} / \mathrm{R}$. Adiponectin participates in the regulation of inflammatory responses in multiple cell types, including cardiac cells and macrophages. ${ }^{16,33,35}$ We have demonstrated that adiponectin inhibits agonist-stimulated TNF-a production in cardiac myocytes and macrophages. ${ }^{16,36}$ Adiponectin is also reported to stimulate production of IL-10 in porcine and human monocyte-derived macrophages. ${ }^{35,37}$ It has been demonstrated that IL-10knockout mice have increased myocardial damage after I/R. ${ }^{38}$ In this study, we found that adiponectin treatment decreased TNF- $a$ expression and increased IL-10 expression in the myocardium after I/R. Therefore, adiponectin may contribute to protection against acute ischemic injury in the heart by perturbing the network of pro- and anti-inflammatory cytokines, including TNF- $a$ and IL-10. 
Apoptosis is a major component in the death of cardiac myocytes, and limitation of apoptosis represents an important therapeutic target during I/R. ${ }^{20,39}$ In this study, administration of adiponectin diminished myocardial apoptosis in the hearts of pigs after I/ R. Previously, we and other groups demonstrated that adiponectin suppresses apoptosis of cardiac and endothelial cells under ischemic conditions in vitro and in vivo. ${ }^{16,40}$ Thus, the ability of adiponectin to protect against infarct formation is also due, at least in part, to its ability to prevent cell death in the myocardium.

Tao et $\mathrm{al}^{41}$ reported that adiponectin-mediated protection from I/R injury is linked to inhibition of excess peroxynitrite-induced oxidative and nitrative stress. Adiponectin also suppresses excess reactive oxygen species production in endothelial cells. ${ }^{42}$ Consistent with these observations, we demonstrated that adiponectin treatment increased BAP levels and decreased d-ROM levels after I/R. Recently, BAP and d-ROM levels have been used to evaluate oxidative status, and their significance as clinical markers has been reported. ${ }^{23,43}$ BAP reflects serum antioxidant capacity, and d-ROM levels represent the total level of peroxidized metabolites. $^{22,23,43}$ Thus, reduction of reactive oxygen species and reactive nitrogen species may contribute to the protective action of adiponectin treatment on acute myocardial injury.

Adiponectin has been shown to promote ischemia-induced revascularization in mouse models of vascular insufficiency and myocardial infarction. ${ }^{12,44}$ In contrast, no significant difference in capillary density was detected between adiponectin-treated and control pigs at 24 hours after injury (data not shown), suggesting that the infarct-sparing action of adiponectin is not due to modulation of revascularization at this early time point.

This study has several limitations. First, adiponectin protein was given via catheter lumen during the first 10 minutes of a 45-minute period of ischemia. This represents a small temporal difference from giving the agent as pretreatment and may not offer compelling support for adiponectin in the clinical setting. Thus, additional experimental studies will be required to assess I/R injury in large-animal models after adiponectin injection at various time points. However, our previous work in the rodent model has shown that the 1-time systemic administration of recombinant adiponectin protein to wild-type mice reduced infarct size, and this therapeutic effect was achieved regardless of whether adiponectin protein was administered 30 minutes before the induction of ischemia, during ischemia, or 15 minutes after reperfusion. ${ }^{16}$ Second, we did not assess the impact of adiponectin on longterm cardiac remodeling and scar formation, and an examination of adiponectin's effects on chronic ischemia in a large-animal model will be required to elucidate these issues. Third, the incidence of VF during I/R was significantly lower in adiponectin-treated than in control pigs. Although it is reasonable to speculate that supplementation with adiponectin directly prevents the occurrence of VF after AMI, direct experimental evidence by electrophysiological monitoring is lacking at this time.

In conclusion, a 1-time administration of adiponectin reduced myocardial infarct size and improved cardiac function after I/R in a preclinical pig model, which was accompanied by suppression of inflammation, apoptosis, and oxidative stress. A single intracoronary injection of adiponectin during percutaneous coronary intervention could be a useful adjunctive therapy for AMI.

\section{Supplementary Material}

Refer to Web version on PubMed Central for supplementary material. 


\section{Acknowledgments}

We thank Boston Scientific Japan for allowing us to use their animal laboratory (Miyazaki T\&E Center, Miyazaki, Japan). We gratefully acknowledge the technical assistance of Naoki Komaki, Takao Kawaguchi, Hiromi Kanasugi, Shinobu Ando, Kazuko Ishikawa, Koichi Yamaguchi, Takahiro Uryu, Kazuyo Noda, Takuya Kan, Yuichi Hayashi, and Yutaka Kose.

Sources of Funding This work was supported by a grant-in-aid for Young Scientists A and the Japan Cardiovascular Research Foundation to R. Shibata.

\section{References}

1. Eisenberg MS, Mengert TJ. Cardiac resuscitation. N Engl J Med. 2001; 344:1304-1313. [PubMed: 11320390]

2. Lange RA, Hillis LD. Immediate angioplasty for acute myocardial infarction. N Engl J Med. 1993; 328:726-728. [PubMed: 8433733]

3. An international randomized trial comparing four thrombolytic strategies for acute myocardial infarction. The GUSTO investigators. N Engl J Med. 1993; 329:673-682. [PubMed: 8204123]

4. Verma S, Fedak PW, Weisel RD, Butany J, Rao V, Maitland A, Li RK, Dhillon B, Yau TM. Fundamentals of reperfusion injury for the clinical cardiologist. Circulation. 2002; 105:2332-2336. [PubMed: 12021216]

5. Reilly MP, Rader DJ. The metabolic syndrome: more than the sum of its parts? Circulation. 2003; 108:1546-1551. [PubMed: 14517150]

6. Orlander PR, Goff DC, Morrissey M, Ramsey DJ, Wear ML, Labarthe DR, Nichaman MZ. The relation of diabetes to the severity of acute myocardial infarction and post-myocardial infarction survival in Mexican-Americans and non-Hispanic whites. The Corpus Christi Heart Project. Diabetes. 1994; 43:897-902. [PubMed: 8013754]

7. Carrabba N, Valenti R, Parodi G, Santoro GM, Antoniucci D. Left ventricular remodeling and heart failure in diabetic patients treated with primary angioplasty for acute myocardial infarction. Circulation. 2004; 110:1974-1979. [PubMed: 15451792]

8. Parodi G, Carrabba N, Santoro GM, Memisha G, Valenti R, Buonamici P, Dovellini EV, Antoniucci D. Heart failure and left ventricular remodeling after reperfused acute myocardial infarction in patients with hypertension. Hypertension. 2006; 47:706-710. [PubMed: 16520403]

9. Ouchi N, Kihara S, Funahashi T, Matsuzawa Y, Walsh K. Obesity, adiponectin and vascular inflammatory disease. Curr Opin Lipidol. 2003; 14:561-566. [PubMed: 14624132]

10. Maeda N, Shimomura I, Kishida K, Nishizawa H, Matsuda M, Nagaretani H, Furuyama N, Kondo H, Takahashi M, Arita Y, Komuro R, Ouchi N, Kihara S, Tochino Y, Okutomi K, Horie M, Takeda S, Aoyama T, Funahashi T, Matsuzawa Y. Diet-induced insulin resistance in mice lacking adiponectin/ACRP30. Nat Med. 2002; 8:731-737. [PubMed: 12068289]

11. Ohashi K, Kihara S, Ouchi N, Kumada M, Fujita K, Hiuge A, Hibuse T, Ryo M, Nishizawa H, Maeda N, Maeda K, Shibata R, Walsh K, Funahashi T, Shimomura I. Adiponectin replenishment ameliorates obesity-related hypertension. Hypertension. 2006; 47:1108-1116. [PubMed: 16651465]

12. Shibata R, Ouchi N, Kihara S, Sato K, Funahashi T, Walsh K. Adiponectin stimulates angiogenesis in response to tissue ischemia through stimulation of AMP-activated protein kinase signaling. J Biol Chem. 2004; 279:28670-28674. [PubMed: 15123726]

13. Shibata R, Ouchi N, Ito M, Kihara S, Shiojima I, Pimentel DR, Kumada M, Sato K, Schiekofer S, Ohashi K, Funahashi T, Colucci WS, Walsh K. Adiponectin-mediated modulation of hypertrophic signals in the heart. Nat Med. 2004; 10:1384-1389. [PubMed: 15558058]

14. Liao Y, Takashima S, Maeda N, Ouchi N, Komamura K, Shimomura I, Hori M, Matsuzawa Y, Funahashi T, Kitakaze M. Exacerbation of heart failure in adiponectin-deficient mice due to impaired regulation of AMPK and glucose metabolism. Cardiovasc Res. 2005; 67:705-713. [PubMed: 15907819] 
15. Takahashi T, Saegusa S, Sumino H, Nakahashi T, Iwai K, Morimoto S, Kanda T. Adiponectin replacement therapy attenuates myocardial damage in leptin-deficient mice with viral myocarditis. J Int Med Res. 2005; 33:207-214. [PubMed: 15790132]

16. Shibata R, Sato K, Pimentel DR, Takemura Y, Kihara S, Ohashi K, Funahashi T, Ouchi N, Walsh $\mathrm{K}$. Adiponectin protects against myocardial ischemia-reperfusion injury through AMPK- and COX-2-dependent mechanisms. Nat Med. 2005; 11:1096-1103. [PubMed: 16155579]

17. Shibata R, Numaguchi Y, Matsushita K, Sone T, Kubota R, Ohashi T, Ishii M, Kihara S, Walsh K, Ouchi N, Murohara T. Usefulness of adiponectin to predict myocardial salvage following successful reperfusion in patients with acute myocardial infarction. Am J Cardiol. 2008; 101:1712-1715. [PubMed: 18549845]

18. Shimano M, Inden Y, Yoshida Y, Tsuji Y, Tsuboi N, Okada T, Yamada T, Murakami Y, Takada Y, Hirayama H, Murohara T. Does RV lead positioning provide additional benefit to cardiac resynchronization therapy in patients with advanced heart failure? Pacing Clin Electrophysiol. 2006; 29:1069-1074. [PubMed: 17038138]

19. Frangogiannis NG, Smith CW, Entman ML. The inflammatory response in myocardial infarction. Cardiovasc Res. 2002; 53:31-47. [PubMed: 11744011]

20. Rupinder SK, Gurpreet AK, Manjeet S. Cell suicide and caspases. Vascul Pharmacol. 2007; 46:383-393. [PubMed: 17382599]

21. Dhalla NS, Elmoselhi AB, Hata T, Makino N. Status of myocardial antioxidants in ischemiareperfusion injury. Cardiovasc Res. 2000; 47:446-456. [PubMed: 10963718]

22. Ridker PM, Brown NJ, Vaughan DE, Harrison DG, Mehta JL. Established and emerging plasma biomarkers in the prediction of first atherothrombotic events. Circulation. 2004; 109:IV-6-IV-19. [PubMed: 15226246]

23. Komatsu F, Kudoh H, Kagawa Y. Evaluation of oxidative stress and effectiveness of low-dose glucocorticoid therapy on exacerbation of chronic obstructive pulmonary disease. J Gerontol A Biol Sci Med Sci. 2007; 62:459-464. [PubMed: 17452743]

24. Valina C, Pinkernell K, Song YH, Bai X, Sadat S, Campeau RJ, Le Jemtel TH, Alt E. Intracoronary administration of autologous adipose tissue-derived stem cells improves left ventricular function, perfusion, and remodelling after acute myocardial infarction. Eur Heart J. 2007; 28:2667-2677. [PubMed: 17933755]

25. Inagaki K, Chen L, Ikeno F, Lee FH, Imahashi K, Bouley DM, Rezaee M, Yock PG, Murphy E, Mochly-Rosen D. Inhibition of delta-protein kinase $C$ protects against reperfusion injury of the ischemic heart in vivo. Circulation. 2003; 108:2304-2307. [PubMed: 14597593]

26. Kojima S, Funahashi T, Sakamoto T, Miyamoto S, Soejima H, Hokamaki J, Kajiwara I, Sugiyama S, Yoshimura M, Fujimoto K, Miyao Y, Suefuji H, Kitagawa A, Ouchi N, Kihara S, Matsuzawa Y, Ogawa $H$. The variation of plasma concentrations of a novel, adipocyte derived protein, adiponectin, in patients with acute myocardial infarction. Heart. 2003; 89:667. [PubMed: 12748233]

27. Kojima S, Funahashi T, Otsuka F, Maruyoshi H, Yamashita T, Kajiwara I, Shimomura H, Miyao Y, Fujimoto K, Sugiyama S, Sakamoto T, Yoshimura M, Ogawa H. Future adverse cardiac events can be predicted by persistently low plasma adiponectin concentrations in men and marked reductions of adiponectin in women after acute myocardial infarction. Atherosclerosis. 2007; 194:204-213. [PubMed: 16970953]

28. Shibata R, Sato K, Kumada M, Izumiya Y, Sonoda M, Kihara S, Ouchi N, Walsh K. Adiponectin accumulates in myocardial tissue that has been damaged by ischemia-reperfusion injury via leakage from the vascular compartment. Cardiovasc Res. 2007; 74:471-479. [PubMed: 17362898]

29. Nishimura M, Izumiya Y, Higuchi A, Shibata R, Qiu J, Kudo C, Shin HK, Moskowitz MA, Ouchi N. Adiponectin prevents cerebral ischemic injury through endothelial nitric oxide synthasedependent mechanisms. Circulation. 2008; 117:216-223. [PubMed: 18158361]

30. Okamoto Y, Arita Y, Nishida M, Muraguchi M, Ouchi N, Takahashi M, Igura T, Inui Y, Kihara S, Nakamura T, Yamashita S, Miyagawa J, Funahashi T, Matsuzawa Y. An adipocyte-derived plasma protein, adiponectin, adheres to injured vascular walls. Horm Metab Res. 2000; 32:47-50. [PubMed: 10741683] 
31. Yamauchi T, Kamon J, Ito Y, Tsuchida A, Yokomizo T, Kita S, Sugiyama T, Miyagishi M, Hara K, Tsunoda M, Murakami K, Ohteki T, Uchida S, Takekawa S, Waki H, Tsuno NH, Shibata Y, Terauchi Y, Froguel P, Tobe K, Koyasu S, Taira K, Kitamura T, Shimizu T, Nagai R, Kadowaki T. Cloning of adiponectin receptors that mediate antidiabetic metabolic effects. Nature. 2003; 423:762-769. [PubMed: 12802337]

32. Hug C, Wang J, Ahmad NS, Bogan JS, Tsao TS, Lodish HF. T-cadherin is a receptor for hexameric and high-molecular-weight forms of Acrp30/adiponectin. Proc Natl Acad Sci U S A. 2004; 101:10308-10313. [PubMed: 15210937]

33. Takemura Y, Ouchi N, Shibata R, Aprahamian T, Kirber MT, Summer RS, Kihara S, Walsh K. Adiponectin modulates inflammatory reactions via calreticulin receptor-dependent clearance of early apoptotic bodies. J Clin Invest. 2007; 117:375-386. [PubMed: 17256056]

34. Hebbard LW, Garlatti M, Young LJ, Cardiff RD, Oshima RG, Ranscht B. T-cadherin supports angiogenesis and adiponectin association with the vasculature in a mouse mammary tumor model. Cancer Res. 2008; 68:1407-1416. [PubMed: 18316604]

35. Kumada M, Kihara S, Ouchi N, Kobayashi H, Okamoto Y, Ohashi K, Maeda K, Nagaretani H, Kishida K, Maeda N, Nagasawa A, Funahashi T, Matsuzawa Y. Adiponectin specifically increased tissue inhibitor of metalloproteinase-1 through interleukin-10 expression in human macrophages. Circulation. 2004; 109:2046-2049. [PubMed: 15096450]

36. Summer R, Little FF, Ouchi N, Takemura Y, Aprahamian T, Dwyer D, Fitzsimmons K, Suki B, Parameswaran H, Fine A, Walsh K. Alveolar macrophage activation and an emphysema-like phenotype in adiponectin-deficient mice. Am J Physiol Lung Cell Mol Physiol. 2008; 294:L1035L1042. [PubMed: 18326826]

37. Wulster-Radcliffe MC, Ajuwon KM, Wang J, Christian JA, Spurlock ME. Adiponectin differentially regulates cytokines in porcine macrophages. Biochem Biophys Res Commun. 2004; 316:924-929. [PubMed: 15033490]

38. Hayward R, Nossuli TO, Scalia R, Lefer AM. Cardioprotective effect of interleukin-10 in murine myocardial ischemia-reperfusion. Eur J Pharmacol. 1997; 334:157-163. [PubMed: 9369344]

39. Scarabelli TM, Gottlieb RA. Functional and clinical repercussions of myocyte apoptosis in the multifaceted damage by ischemia/reperfusion injury: old and new concepts after 10 years of contributions. Cell Death Differ. 2004; 11:S144-S152. [PubMed: 15608693]

40. Kobayashi H, Ouchi N, Kihara S, Walsh K, Kumada M, Abe Y, Funahashi T, Matsuzawa Y. Selective suppression of endothelial cell apoptosis by the high molecular weight form of adiponectin. Circ Res. 2004; 94:e27-e31. [PubMed: 14752031]

41. Tao L, Gao E, Jiao X, Yuan Y, Li S, Christopher TA, Lopez BL, Koch W, Chan L, Goldstein BJ, Ma XL. Adiponectin cardioprotection after myocardial ischemia/reperfusion involves the reduction of oxidative/nitrative stress. Circulation. 2007; 115:1408-1416. [PubMed: 17339545]

42. Ouedraogo R, Wu X, Xu SQ, Fuchsel L, Motoshima H, Mahadev K, Hough K, Scalia R, Goldstein BJ. Adiponectin suppression of high-glucose-induced reactive oxygen species in vascular endothelial cells: evidence for involvement of a cAMP signaling pathway. Diabetes. 2006; 55:1840-1846. [PubMed: 16731851]

43. Neuman RB, Bloom HL, Shukrullah I, Darrow LA, Kleinbaum D, Jones DP, Dudley SC Jr. Oxidative stress markers are associated with persistent atrial fibrillation. Clin Chem. 2007; 53:1652-1657. [PubMed: 17599958]

44. Shibata R, Izumiya Y, Sato K, Papanicolaou K, Kihara S, Colucci WS, Sam F, Ouchi N, Walsh K. Adiponectin protects against the development of systolic dysfunction following myocardial infarction. J Mol Cell Cardiol. 2007; 42:1065-1074. [PubMed: 17499764] 


\section{CLINICAL PERSPECTIVE}

Acute myocardial infarction (AMI) is a major cause of death in industrial countries. Reperfusion therapy immediately after onset of AMI has been shown to limit infarct size and preserve cardiac function. However, successful reperfusion determined by coronary angiography is not always accompanied by adequate reperfusion at the heart tissue level and improvement of cardiac dysfunction. Therefore, it is reasonable to develop a promising adjunctive therapy in patients with AMI. Adiponectin plays a protective role in the development of obesity-linked disorders such as AMI. Here, we explored the effectiveness and feasibility of adiponectin treatment for AMI in a preclinical animal model that closely reproduces the current procedural management of AMI in humans. The left anterior descending coronary artery was occluded in pigs for 45 minutes and then reperfused for 24 hours. Recombinant adiponectin protein was given as a bolus intracoronary injection during ischemia. A 1-time administration of adiponectin reduced myocardial infarct size and improved cardiac function after ischemia-reperfusion in this preclinical pig model and was accompanied by suppression of inflammation, apoptosis, and oxidative stress. A single intracoronary injection of adiponectin during percutaneous coronary intervention could be a useful adjunctive therapy for AMI. 
A

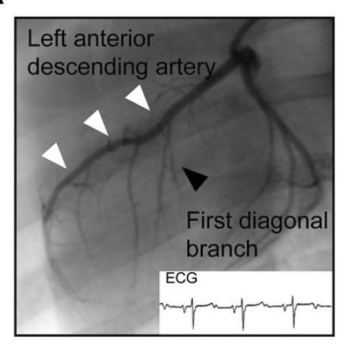

C

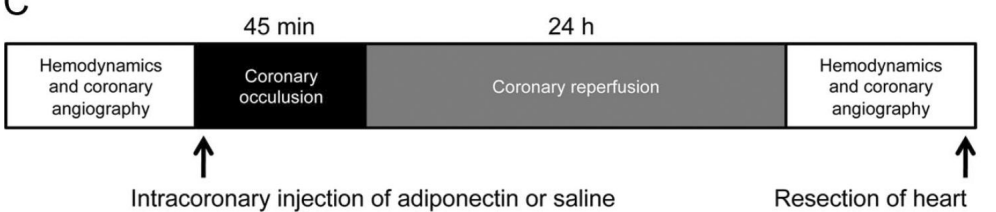

B

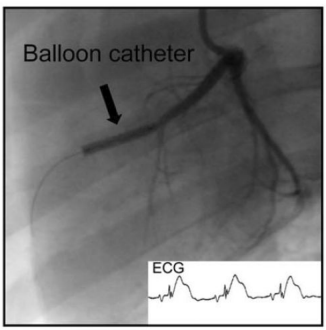

Resection of heart

Figure 1.

Induction of myocardial $\mathrm{I} / \mathrm{R}$ in pigs. A, Baseline coronary angiogram and ECG, showing the LAD (white arrows) and the first diagonal branch (black arrow). B, Coronary angiogram and ECG during the procedure, with the inflated balloon in the LAD distal to the first diagonal branch (black arrow). C, Schematic illustration of the experimental protocol. 
A

Figure 2.

Adiponectin reduced infarct size after I/R injury. A, Representative photographs of the heart before resection from the control group (top) and the adiponectin group (bottom) at 24 hours after I/R injury. B, Representative photographs of myocardial tissues from the control group (left) and the adiponectin group (right) at 24 hours after I/R injury. The nonischemic area is indicated by blue, AAR by red, and the IA by white. C, Quantification of infarct size in the control group $(n=6)$ and the adiponectin group $(n=5)$. AAR/LV indicates ratio of AAR to $\mathrm{LV}$ area; IA/AAR, ratio of IA to AAR; and IA/LV, ratio of IA to LV area. D, Troponin I values in blood samples. Plasma troponin I levels were measured at 24 hours after operation. Results are presented as mean \pm SE. 

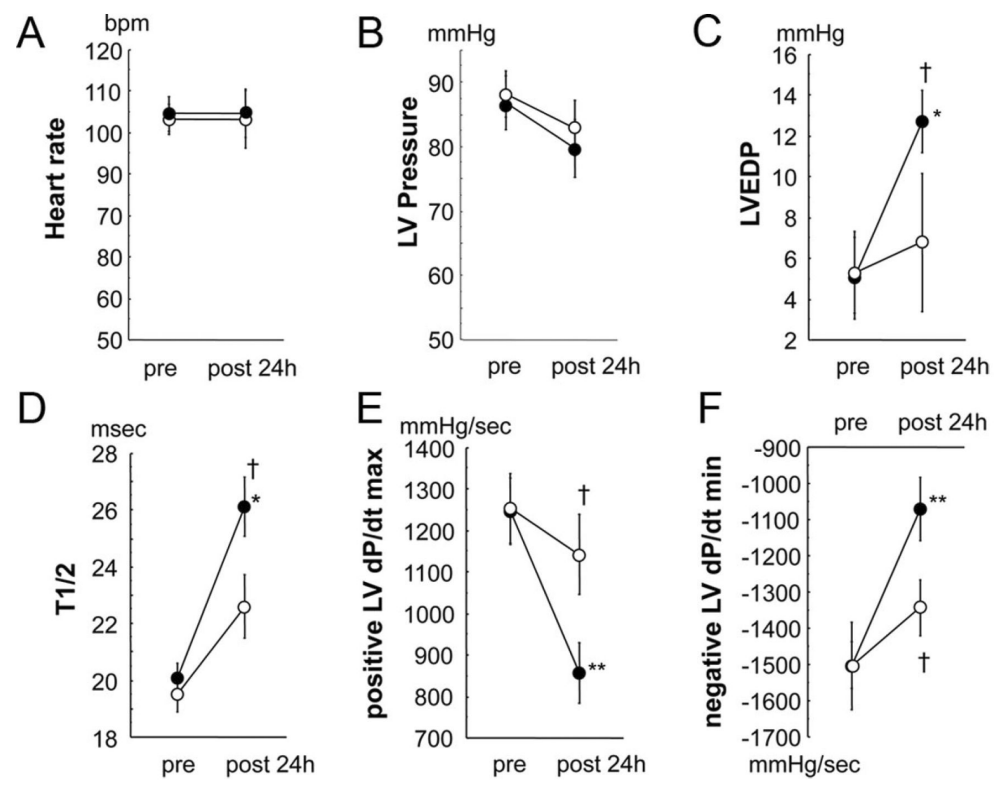

Figure 3.

Effect of adiponectin treatment on cardiac function. Heart rate (A), LV pressure (B), LV end-diastolic pressure (EDP; C), $\mathrm{T}_{1 / 2}$ (D), $\mathrm{LV} \mathrm{d} P / \mathrm{d} t_{\max }(\mathrm{E})$, and $\mathrm{LV} \mathrm{d} P / \mathrm{d} t_{\min }(\mathrm{F})$ in the control and adiponectin groups at baseline and 24 hours after I/R injury (black circles, control group, $\mathrm{n}=7$; white circles, adiponectin group, $\mathrm{n}=7)$. $* P<0.05, * * P<0.01$ vs baseline; $\dagger P<0.05$ vs control. 


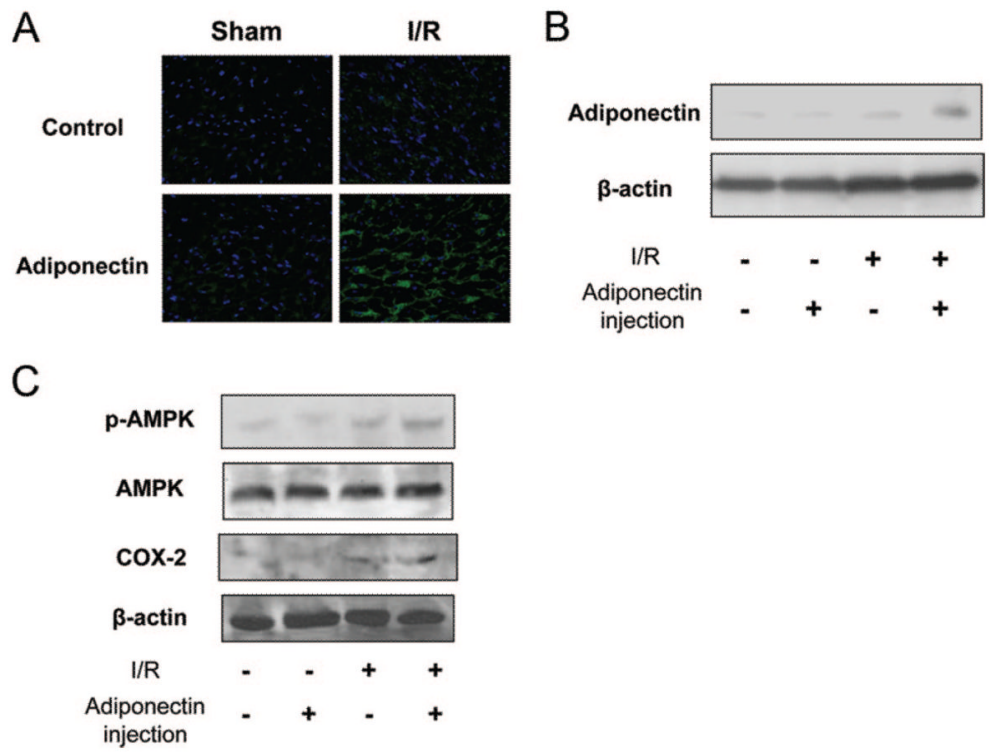

Figure 4.

Exogenous adiponectin accumulates in the ischemic heart. A, Representative immunostaining of human adiponectin from heart sections at 24 hours after sham operation or I/R injury (magnification, $\times 400$ ). B, Detection of administrated human adiponectin in heart tissues at 24 hours after I/R injury by Western blot analysis. C, Phosphorylation of AMP-activated protein kinase (PK) and the expression of cyclooxygenase (COX)-2 in heart tissues from pigs in the control and adiponectin groups at 24 hours after sham operation or I/ R injury. 
A

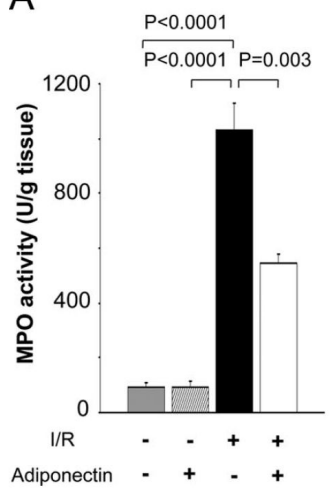

B

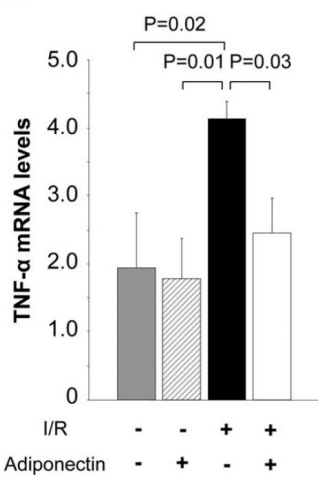

C

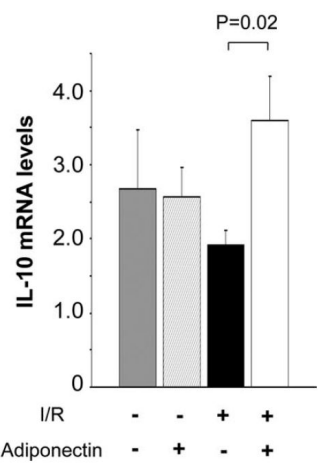

Figure 5.

Effect of adiponectin treatment on inflammatory status after I/R injury. A, Myeloperoxidase (MPO) activity in the control and adiponectin groups at 24 hours after sham operation or I/R injury ( $\mathrm{n}=5$ for each group). Myocardial levels of TNF-a mRNA (B) and IL-10 mRNA (C) in the control and adiponectin groups at 24 hours after sham operation or I/R injury. TNF-a or IL-10 mRNA levels were quantified by real-time reverse transcription polymerase chain reaction ( $n=5$ for each group) and expressed relative to $\beta$-actin mRNA levels. 
A
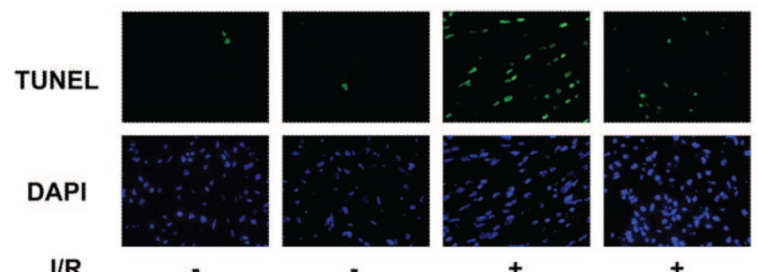

$+$

Adiponectin

$\mathrm{B}$

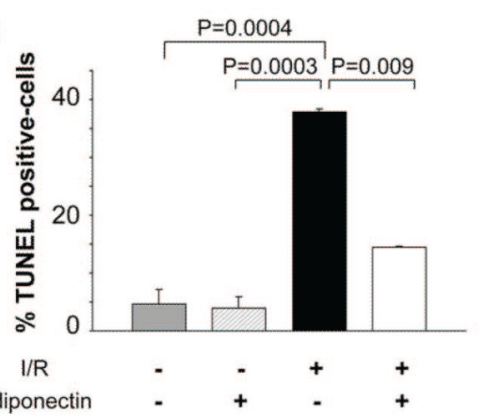

C

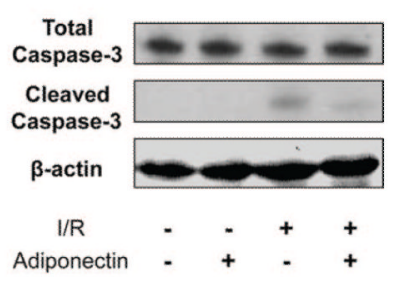

Figure 6.

Effect of adiponectin treatment on apoptotic activity after I/R injury. A, Representative photographs of TUNEL-stained heart sections in the control and adiponectin groups at 24 hours after sham operation or I/R injury (magnification, $\times 400$ ). Apoptotic nuclei were identified by TUNEL staining (green) and total nuclei by $4^{\prime}, 6$-diamidino-2-phenylindole (DAPI) counterstaining (blue). B, Quantitative analysis of apoptotic nuclei from heart tissues in the control and adiponectin groups at 24 hours after sham operation or I/R injury. TUNEL-positive nuclei are expressed as a percentage of the total number of nuclei. C, Detection of caspase- 3 cleavage in heart tissues at 24 hours after I/R injury by Western blot analysis. 
A

CARR.U.

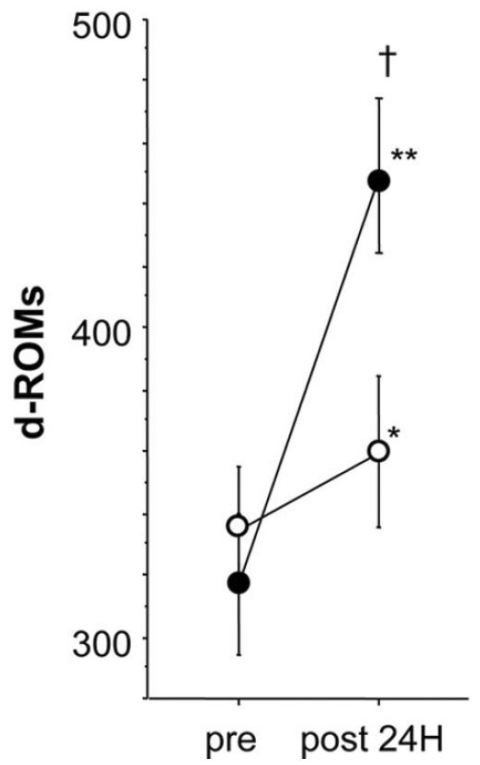

B

$\mathrm{mmol} / \mathrm{l}$

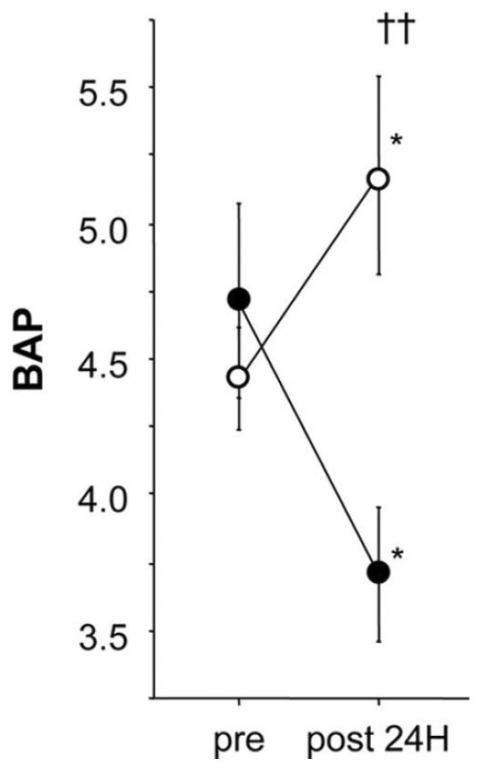

Figure 7.

Effect of adiponectin treatment on oxidative damage after I/R injury. d-ROMs (A) and BAP (B) in the control and adiponectin groups at baseline (pre) and 24 hours after (post) I/R injury (black circles, control group, $\mathrm{n}=7$; white circles, adiponectin group, $\mathrm{n}=7$ ). $* P<0.05$, $* * P<0.01$ vs baseline, $\dagger P<0.05, \dagger \dagger P<0.05$ vs control. 


\section{Table}

The Incidence of VF, Mortality, and Outcome

\begin{tabular}{lrrl}
\hline & Control (n=9), \% & Adiponectin (n=7), \% & \multicolumn{1}{l}{} \\
\hline VF during procedure & 89 & 29 & 0.01 \\
Total mortality & 22 & 0 & 0.48 \\
Death during procedure & 0 & 0 & 1.0 \\
Death within 24 h & 22 & 0 & 0.48 \\
\hline
\end{tabular}

